\title{
DETERMINAÇÃO DO PERÍODO MAIS PROPÍCIO ÀS OCORRÊNCIAS DE INCÊNDIOS EM VEGETAÇÃO NA ÁREA URBANA DE JUIZ DE FORA, MG ${ }^{1}$
}

\author{
Fillipe Tamiozzo Pereira Torres², Guido Assunção Ribeiro ${ }^{3}$, Sebastião Venâncio Martins ${ }^{3}$ e \\ Gumercindo Souza Lima ${ }^{3}$
}

\begin{abstract}
Resumo - Os incêndios em vegetação podem provocar severos danos ao ambiente, além de consequências econômicas consideráveis, como a destruição de hábitats, a queima de madeira e os custos para o seu combate. Para estabelecer políticas de controle e prevenção, faz-se necessário conhecer o perfil dos incêndios. As estatísticas de ocorrência dos incêndios em vegetação são as principais ferramentas para se traçar seu perfil. Com esses dados, pode-se planejar o controle de modo mais eficiente, diminuindo gastos, tempo e riscos em seu combate. O objetivo deste estudo visou à determinação da época do ano e horário de maiores ocorrências de incêndios em vegetação no Município de Juiz de Fora, MG. Para isso, foi utilizada uma série temporal de 10 anos (1995 - 2004), com dados de ocorrências de incêndios e elementos climáticos na área urbana do município. De acordo com os resultados, foi caracterizado o período de junho a outubro como a estação normal do fogo. Em relação às horas do dia, o período das 10 às 20 h foi o que concentrou o maior número de ocorrências, tendo seu pico entre 15 e $16 \mathrm{~h}$.
\end{abstract}

Palavras-chave: Fogo, Horário e Época do ano.

\section{DETERMINATION OF THE MOST FAVORABLE PERIOD FOR THE OCCURRENCES OF VEGETATION FIRES IN THE URBAN AREA OF JUIZ DE FORA, MG}

\begin{abstract}
Vegetation fires can provoke severe damage to the environment as well as considerable economic consequences, such as the destruction of habitats, the burning of wood and costs for combating them. To establish politics for control and prevention, it is necessary to know the profile of fire. The statistics of occurrence of vegetation fires are the main tools to draw your profile. With this data, we can plan to control them more efficiently by reducing costs, time and risk in their combat. The objective of this study seeks to determine the period of the year and schedule of larger occurrences of vegetation fires in the city of Juiz de Fora (MG). For that a 10 year temporary series was used (1995 - 2004) with data of occurrences of fires and climatic elements in the city. According to the results, the period from June to October as the normal fire season was characterized. Hourly, from 10:00 to 20:00 hours the largest number of occurrences was concentrated and peaks were between 15:00 and 16:00 h.
\end{abstract}

Keywords: Fires, Schedule and Period of the year.

\section{INTRODUÇÃO}

De acordo com Soares (1995), o fogo é um fenômeno natural que sempre existiu na superfície do planeta e também um dos responsáveis pela predominância de vários ecossistemas terrestres. Contudo, fora de controle, esse fenômeno causa diversas perdas de ordens econômica, social e ambiental.
Os incêndios em vegetação podem provocar prejuízos importantes ao ambiente, como os danos à fauna e à flora, às pessoas, inclusive com perdas de vidas, além de consequências econômicas consideráveis, como a destruição de hábitats, a queima de madeira e os custos para seu controle (FIEDLER et al., 2006).

\footnotetext{
${ }^{1}$ Recebido em 25.08.2008 e aceito para publicação em 14.10.2009.

${ }^{2}$ Fundação Municipal Irailda Ribeiro dos Santos, FUNIR, Brasil. E-mail: <torresftp@yahoo.com.br>.

${ }^{3}$ Departamento de Engenharia Florestal, Universidade Federal de Viçosa, UFV, Brasil. E-mail: < gribeiro@ufv.br>e < venancio@ufv.br>.
} 
Apesar de anos de estudo científico e de toda a atenção da mídia em relação aos incêndios em vegetação, os efeitos que eles causam ao ambiente ainda têm sido ignorados (SILVA et al., 2003).

Para Torres e Ribeiro (2008), a maior parte dos incêndios tem origem humana, principalmente aqueles provocados intencionalmente, por vingança ou desequilíbrio emocional. Contudo, são os fatores climáticos, como seca e velocidade do vento, ou o relevo, que influenciam na sua propagação e determinam os seus efeitos devastadores. Essa situação vem-se agravando em muitos países, em consequência do acúmulo de material combustível e, principalmente, devido ao crescimento populacional.

Segundo Santos et al. (2006), em recente estudo sobre o perfil dos incêndios em vegetação no Brasil em áreas protegidas no período de 1998 a 2002, Minas Gerais foi o Estado com maior número de ocorrências registradas. Com relação à área queimada, Minas também ocupou o primeiro lugar. A estação normal do fogo se estendeu de junho a outubro, totalizando $68,87 \%$ do número de ocorrências e 90,76\% das áreas queimadas, destacando-se os meses de agosto e outubro com maior número de ocorrências e os meses de agosto, setembro e outubro com maior área queimada.

Sampaio (1999) afirmou que a proteção da vegetação contra o fogo começa com a prevenção. A melhor maneira de combater um incêndio é evitar que ele ocorra. Considerando que a grande maioria dos incêndios em vegetação é provocada por ação antrópica, eles são, em sua maior parte, teoricamente evitáveis.

Para estabelecer políticas de controle e prevenção, faz-se necessário conhecer o perfil dos incêndios. As estatísticas de ocorrência dos incêndios em vegetação são as principais ferramentas para se traçar esse perfil.

De acordo com Pezzopane et al. (2001), as preocupações com incêndios são constantes nos meses de inverno e primavera em razão, principalmente, dos baixos índices pluviométricos. Contudo, como as condições climáticas variam de acordo com a região e a sazonalidade, esse período pode ser diferente em função da localização da área de estudo.

O objetivo deste trabalho foi estudar a correlação entre as variáveis meteorológicas e as ocorrências de incêndios em vegetação na região urbana do Município de Juiz de Fora, Minas Gerais, definindo a melhor variável para o estabelecimento da estação normal de fogo e o levantamento dos horários de maior ocorrência de incêndios durante o dia.

Segundo Sampaio (1991), a estação normal do fogo corresponde à época do ano em que os fatores climatológicos, principalmente a baixa precipitação e a umidade relativa do ar, favorecem o aparecimento de grande número de incêndios em vegetação.

De acordo com Macedo e Sardinha (1985), a determinação do período mais propício aos incêndios constitui importante ferramenta para a diminuição de prejuízos, riscos e custos em seu combate, visto que permite ações de caráter preventivo pelas entidades responsáveis. Além do mais, conhecendo-se o período de maior concentração das ocorrências desonera o trabalho de levantamento dos dados, aumenta sua eficiência e a caracterização do perfil dos incêndios torna-se mais real.

\section{METODOLOGIA}

Para a realização deste estudo foi utilizada uma série temporal do período entre 1995 e 2004. Os dados meteorológicos foram mensurados na Estação Climatológica Principal localizada no Campus da Universidade Federal de Juiz de Fora. As 3.118 ocorrências de incêndios, na área urbana do município, foram registradas pelo $4^{\circ}$ Batalhão de Bombeiros Militares ( $4^{\circ}$ B.B.M.).

O Município de Juiz de Fora apresenta, de acordo com o IBGE (2000), uma população de 456.432 habitantes. Localiza-se no Sudeste do Estado de Minas Gerais, estando o centro da cidade nas coordenadas $21^{\circ} 41^{\text {' }}$ 20" S e 43 20' 40" W (PJF, 1996).

O clima, de acordo com Köeppen, é do tipo Cwb (tropical de altitude), com chuvas concentradas no período de outubro a abril e estação mais seca de maio a setembro (PJF, 1996).

De acordo com Torres et al. (2008), o déficit hídrico no município ocorre nos meses de junho, julho e agosto, o que tende a aumentar a quantidade de incêndios nesse período.

A estação normal do fogo foi determinada em duas etapas: a) análise dos totais mensais de precipitação, evaporação e insolação e média mensal da umidade relativa do ar, determinando-se qual desses elementos climáticos melhor se relacionou com a quantidade mensal 
de ocorrências, utilizando-se o coeficiente de correlação de Pearson (r); e b) determinado o elemento climático mais correlacionado com as ocorrências, sua distribuição mensal foi analisada em conjunto com a distribuição mensal dos incêndios, estabelecendo-se a estação normal do fogo. As análises foram realizadas com o auxílio do software Statistica (STATSOFT, 1995).

O horário de maior concentração de ocorrências foi definido agrupando-se os incêndios por hora do evento e determinando qual horário concentrou o maior número de ocorrências.

\section{RESULTADOS}

Cerca de 90\% das ocorrências foram registradas em áreas com predomínio de vegetação herbácea, sendo 43,94\% dos incêndios em lotes vagos
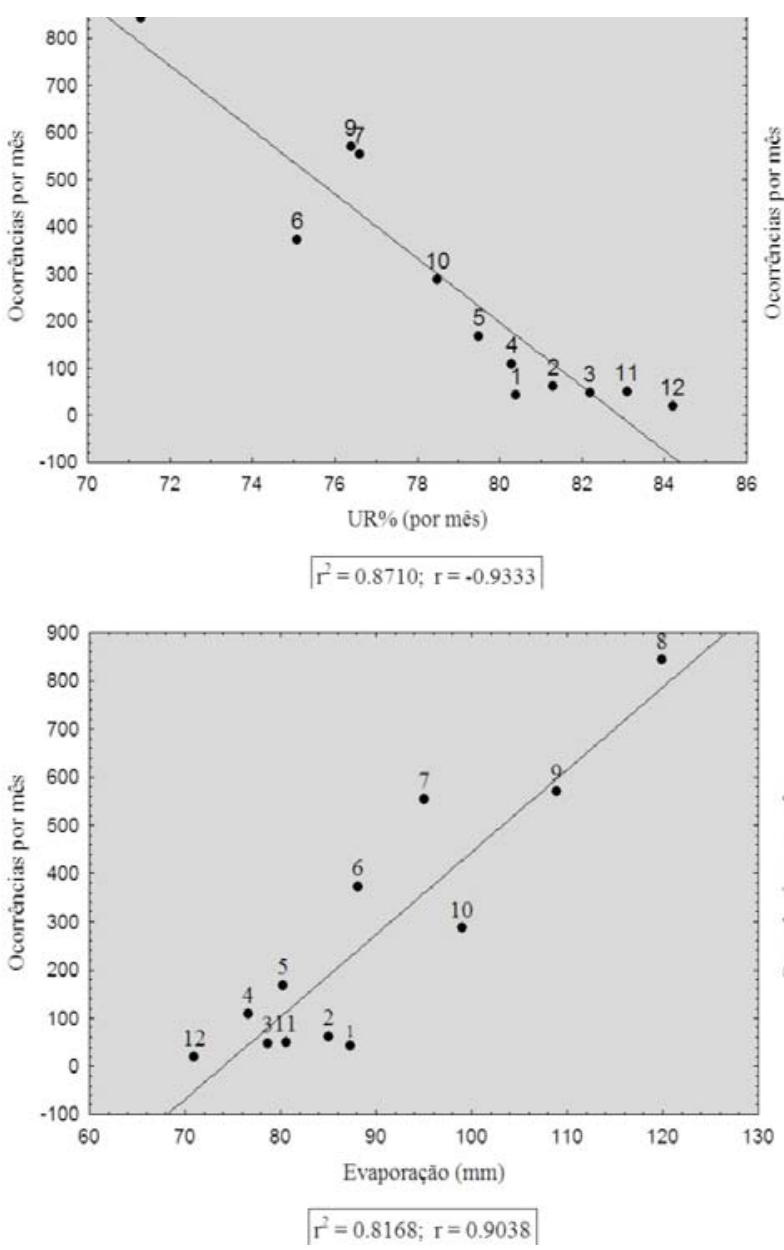

distribuídos pela cidade e 45,43\% em campos e pastos. Com relação à exposição ao Sol, 48\% dos incêndios ocorreram em vertentes voltadas para o norte, $22 \%$ para o oeste, $18 \%$ para o leste e $12 \%$ para o sul.

Os coeficientes de correlação de Pearson (Figura 1) mostram alta correlação entre o total mensal de insolação, evaporação e média mensal de UR e boa correlação do total mensal da precipitação com o número de ocorrências mensais. O total mensal de insolação obteve a maior correlação $(r=-0,9871)$.

Para o ajuste da curva, o modelo linear foi o que melhor se adequou aos elementos UR, insolação e evaporação, enquanto na precipitação o modelo logarítmico foi o mais apropriado.
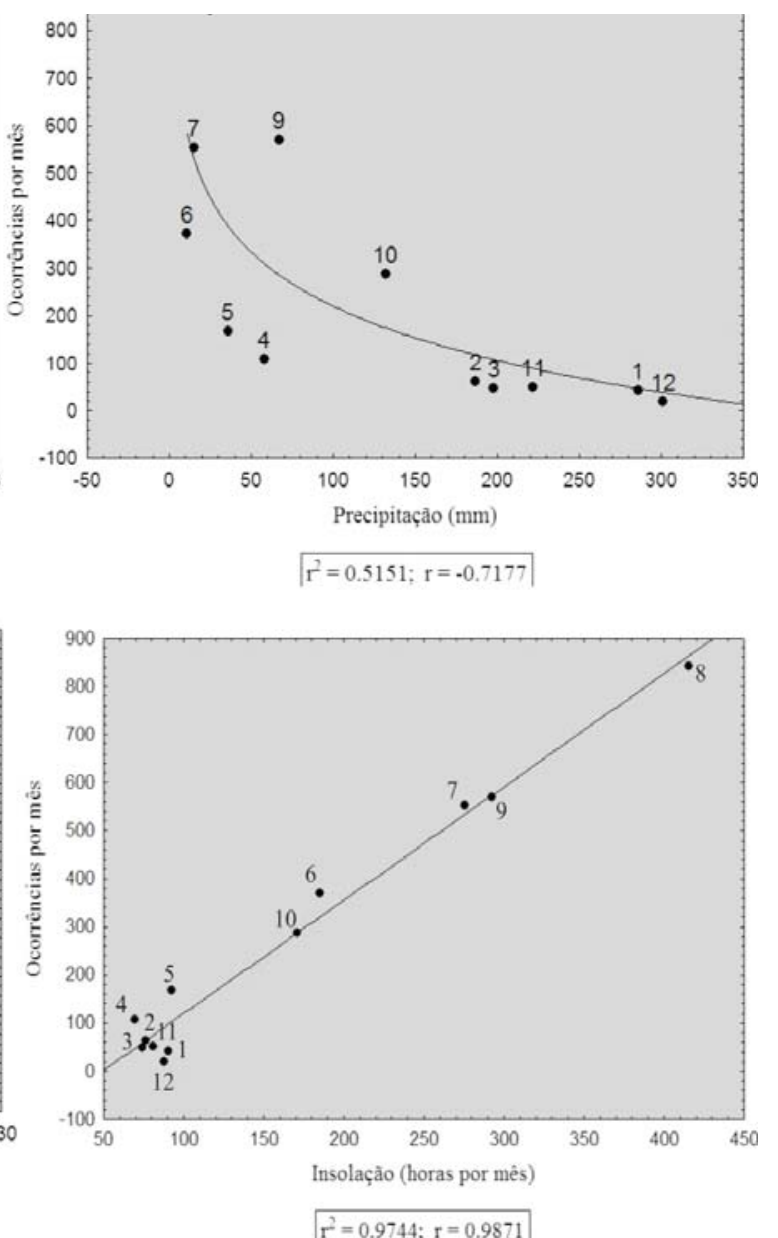

Figura 1 - Número total de ocorrências mensais em função dos valores mensais dos elementos meteorológicos.

Figure 1 - Total number of monthly occurrences in function of the monthly values of the meteorological elements. 
Observou-se, o tempo de resposta do ambiente em relação às mudanças dos valores dos elementos climáticos, e a precipitação apresentou o menor índice de correlação, demonstrando que o sistema necessita de maior tempo de resposta quando há mudança em seus valores. Observou-se ainda, no entanto, que para a insolação esse tempo de resposta foi menor (Figura 2). A partir do aumento da insolação do mês de maio para o mês de junho, de 92 para 185 horas de brilho solar (total por mês), houve aumento simultâneo de 167 para 371 ocorrências, enquanto a queda de 171 horas no mês de outubro até 81 horas no mês de novembro representou diminuição de 286 para 50 ocorrências.

Devido ao maior índice de correlação entre a insolação e as ocorrências e sua relação com os demais elementos climáticos, a estação normal do fogo foi definida em sua função (Figura 2).

Com relação aos horários de maior número de ocorrências, verificou-se que os incêndios tiveram maior intensidade de casos registrados nos horários compreendidos entre as $12 \mathrm{~h}$ e as $16 \mathrm{~h}$ (Figura 3 ), atingindo o menor número de ocorrências por volta das 06 h (Figura 3).

Analisando somente os dois períodos que concentraram o maior número de ocorrências (Figura 4), observou-se crescimento do número de incêndios, atingindo o pico entre 15 e 15h59, quando, após esse horário, houve decréscimo na quantidade de ocorrências. Observou-se, também, desaceleração na queda do número de ocorrências entre 17 h e 19 h.

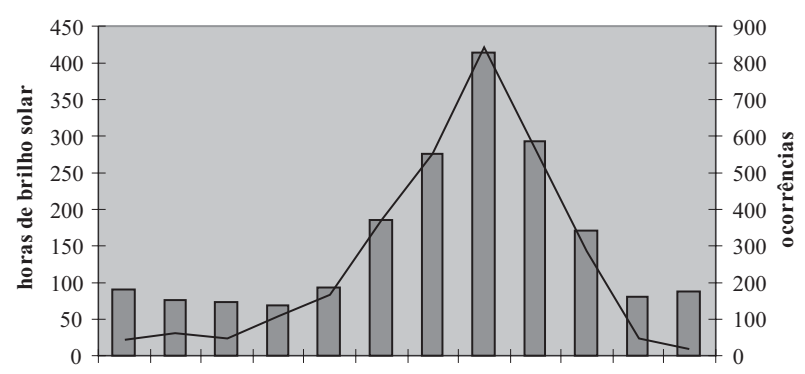

jan fev mar abr mai jun jul ago set out nov dez

$\square$ insolação $-\mathrm{n}^{\circ}$ de ocorrências

Figura 2 - Relação entre o número de ocorrências e a insolação. Figure 2 - Relationship between the number of occurrences and the heatstroke.

R. Árvore, Viçosa-MG, v.34, n.2, p.297-303, 2010

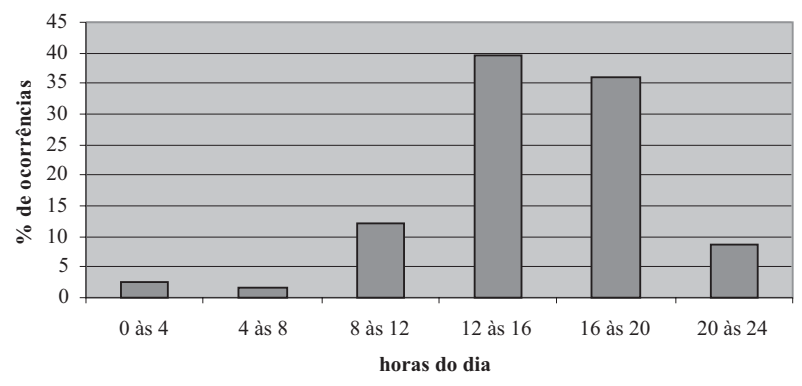

Figura 3 - Porcentagens de ocorrências por hora do dia. Figure 3-Percentages of occurrences for hour of the day.

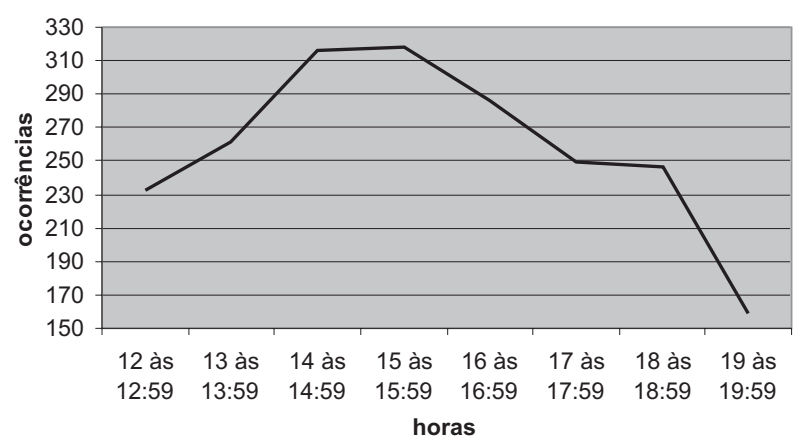

Figura 4- Ocorrências por hora no período de maior concentração de incêndios.

Figure 4-Occurrences per hour in the period of larger concentration of fires.

\section{DISCUSSÃO}

A grande quantidade de incêndios em lotes vagos confirma a influência antrópica sobre as ocorrências, visto que o fogo é utilizado para a limpeza dessas áreas, muitas vezes fugindo do controle do causador.

O alto índice de correlação entre UR e as ocorrências de incêndios (Figura 1) é um fato esperado, uma vez que essa variável está intimamente relacionada com a umidade do material combustível. De acordo com Torres e Ribeiro (2008), a umidade atmosférica é elemento decisivo nos incêndios em vegetação, tendo efeito direto na inflamabilidade dos combustíveis florestais, em que há troca constante de umidade entre a atmosfera e a matéria orgânica. O material seco absorve água de uma atmosfera úmida e a libera quando o ar está seco. A quantidade de umidade que o material morto pode absorver e reter do ar depende, basicamente, da umidade relativa do ar. 
Segundo Soares (1985), o material combustível com alto teor de umidade não queima. Isso se deve à “umidade de extinção”, dada pelo conteúdo de umidade entre 25 e $30 \%$ do material combustível. Umidade acima desse limite impede a combustão e a propagação dos incêndios. O combustível não queima porque é necessária a utilização de grande quantidade de energia para vaporizar a água, reduzindo a quantidade de calor para a combustão propriamente dita.

A correlação entre a precipitação e o número de ocorrências (Figura 1) mostra que a quantidade de chuva afeta diretamente o número de incêndios em vegetação. Para Nunes (2005), apesar de ser fator limitante tanto na ignição quanto na propagação do fogo, o efeito da precipitação muitas vezes é subestimado, talvez pela grande evidência de sua influência sobre os incêndios. Ainda de acordo com esse autor, a ocorrência dos incêndios está associada aos períodos sem chuva. Longos períodos de estiagem afetam o potencial de propagação dos incêndios de diversas maneiras, principalmente pela secagem progressiva do material combustível morto, podendo, inclusive, afetar o teor de umidade da vegetação verde. Isso aumenta a probabilidade de ignição e a facilidade de propagação do incêndio.

A evaporação é , variável pouco estudada e empregada na prevenção de incêndios em vegetação, tendo em vista a maior dificuldade de obtenção dos dados e a interferência que ela sofre de outras variáveis de mais fácil medição. Na Figura 1, mostra-se que, quanto maior a evaporação, maior o número de ocorrências. A evaporação influi na secagem do combustível, devido à perda de umidade para a atmosfera. Quanto maior a evaporação, maior e mais rápida a secagem do material, e consequentemente, maior o perigo de fogo (TORRES et al., 2008).

Ao analisar a correlação entre a insolação, ou a quantidade de horas de brilho solar, e as ocorrências de incêndios (Figura 1), observou-se que, quanto maior a exposição ao Sol, maior a quantidade de ocorrências. A intensidade da insolação está intimamente relacionada à umidade do ar, visto queeste, quando mais seco, menor a quantidade de nuvens formadas, o que aumenta a incidência dos raios solares. A insolação está ligada também à radiação do Sol, e, quanto maior o tempo exposto à luz solar, maior o tempo de exposição à sua radiação. De acordo com Couto e Cândido (1980), a exposição do combustível à insolação provoca, ainda, a evaporação, acelerando sua secagem.
Observa-se, ainda, o tempo de resposta do ambiente em relação às mudanças dos valores dos elementos climáticos, em que o valor de “ $r$ ” mais próximo de zero apresentado pela precipitação, em relação aos outros elementos, pode ser explicado por Sampaio (1991). Esse autor observou que o período de maior ocorrência de incêndios começa dois meses após o início do período de escassez de chuva e termina também dois meses após o final desse período, concluindo que redução da precipitação não corresponde a aumento imediato na ocorrência de incêndios em vegetação, pois o solo e o material combustível continuam úmidos por algum tempo. Aumento na precipitação também não corresponde à redução imediata na ocorrência de incêndios, pois, estando o solo e o material combustível com baixo teor de umidade, as precipitações serão absorvidas até o ponto em que o material combustível não entre mais em ignição.

Os meses de junho, julho, agosto, setembro e outubro apresentaram maior quantidade de ocorrências e maiores valores de insolação. Dessa forma, a variável insolação mostrou maior correlação linear e com resposta imediata entre o seu aumento e o número de ocorrências de incêndios, sendo a sua utilização mais indicada para a definição da estação normal do fogo para as regiões onde essas informações estão disponíveis.

Entre as informações sobre os aspectos ligados à influência dos vetores climáticos, que são conhecidas através dos levantamentos estatísticos, pode-se observar também que os incêndios têm seu pico de intensidade nos horários compreendidos entre 12 h e 16 h (radiação solar mais direta e intensa) (Figura 3).

A radiação solar tende a aumentar a temperatura ambiente, e, com isso há decréscimo na umidade relativa do ar, visto que, pelas leis da Termodinâmica, um corpo ao adquirir calor tende a se expandir. Como o ar não é diferente, com o ganho de calor ele se expande e, com isso, abre espaço para maior quantidade de umidade. Como a umidade relativa do ar é a relação entre a concentração de umidade contida no ar e o total que o ar comporta, os valores relativos diminuem em função do aumento da temperatura.

A temperatura mínima do dia é, no entanto, alcançada instantes antes do primeiro raio solar, o que, dependendo da época do ano, ocorre por volta das 6 h, implicando maior umidade relativa do ar, o que resulta em um número mínimo de ocorrências nesse período.

R. Árvore, Viçosa-MG, v.34, n.2, p.297-303, 2010 
Analisando-se somente os dois períodos que concentraram o maior número de ocorrências (Figura 4), o crescimento verificado do número de incêndios atingindo o pico entre 15 e $16 \mathrm{~h}$ pode ser explicado pelo horário em que é atingida no município a maior temperatura diurna, quando, após esse horário, há decréscimo na quantidade de ocorrências. Essa queda parece estar relacionada à diminuição da temperatura, propiciando aumento na umidade relativa do ar.

No Município de Ubá, MG, distante cerca de 100 km de Juiz de Fora, foi observado, dentro do mesmo período de estudo, que o pico do número de incêndios ocorre $1 \mathrm{~h}$ antes, entre 14 e $15 \mathrm{~h}$. Isso pode se justificar pela maior temperatura do Município de Ubá, que está a cerca de 340 m mais baixo que Juiz de Fora em relação ao nível do mar; essa altitude pode representar, segundo Torres (2008), aumento de quase $2{ }^{\circ} \mathrm{C}$ na temperatura média do município, tendendo a atingir valor crítico mais cedo em Ubá. Essa diferença mostra a modificação do perfil dos incêndios de acordo com pequenas variações espaciais, significando que, quanto menor a extensão espacial da área de estudo, mais confiável é o perfil traçado.

A distribuição das ocorrências de acordo com a exposição das vertentes, mostra o controle climático sobre os incêndios, as vertentes com maior exposição anual são mais suscetíveis aos incêndios, graças à maior temperatura e á menor umidade.

A desaceleração da queda do número de ocorrências entre 17 h e 19 h parece estar relacionada, de acordo com Torres (2008), com o aumento do fluxo de carros e pessoas do final do expediente comercial, aumentando a quantidade de pontas de cigarros jogadas por motoristas e pedestres, o que, de acordo com Soares e Santos (2003), Vosgerau et al. (2006) e Jacobi (2007), aumenta o número de incêndios em áreas próximas a esses fluxos, sobretudo em vias mais movimentadas. Vosgerau et al. (2006) afirmaram, inclusive, que os fumantes foram $72 \%$ das causas registradas de incêndios em vegetação no Paraná, de 1991 a 2001.

\section{CONCLUSÕES}

- O número total de ocorrências de incêndios mensais tiveram maior correlação com o total mensal de insolação (horas de brilho solar) do que com os outros elementos, apesar da alta correlação com a Umidade Relativa do Ar e a Evaporação.

R. Árvore, Viçosa-MG, v.34, n.2, p.297-303, 2010
- Definiu-se como a estação normal do fogo para o Município de Juiz de Fora os meses de junho, julho, agosto, setembro e outubro, sendo o mês de agosto o de maior risco.

- Variáveis meteorológicas como a insolação e a evaporação, não usualmente empregadas em estudos de prevenção contra incêndios em vegetação, apresentaram alta correlação com as ocorrências, indicando que elas deveriam ser mais utilizadas em trabalhos desta natureza.

- A quantidade de ocorrências diárias atingiu seu pico entre 15 h e 16 .

- A variação das condições meteorológicas diurnas e sazonais controlaram os períodos de maior e de menor concentração de ocorrências de incêndios em vegetação.

\section{REFERÊNCIAS}

COUTO, E. A.; CÂNDIDO, J. F. Incêndios

florestais. Viçosa, MG: Universidade Federal de Viçosa, 1980. 101p.

FIEDLER, N. C. et al. Avaliação das condições de trabalho, treinamento, saúde e segurança de brigadistas de combate a incêndios florestais em unidades de conservação do Distrito Federal: estudo de caso. Viçosa: Revista Árvore, v.30, n.1, p.55-63, 2006.

\section{INSTITUTO BRASILEIRO DE GEOGRAFIA E} ESTATÍSTICA - IBGE. Censo Demográfico 2000. Rio de Janeiro: 2000.

JACOBI, L. F. Queimadas acidentais em campo em Santa Maria - RS. 2007. $57 \mathrm{f}$. Tese (Doutorado em Agronomia) - Universidade Federal de Santa Maria, Santa Maria, 2007.

JUIZ DE FORA - Prefeitura. Plano Diretor de Juiz de Fora. Juiz de Fora: Concorde, 1996.

MACEDO, W.; SARDINHA, A. M. Fogos

florestais. Vila Real: Universidade de Trás-osMontes e Alto Douro, 1985. 430p.

NUNES, J. R. S. FMA+ - Um novo índice de perigo de incêndios florestais para o Estado do Paraná - Brasil. 2005. $150 f$. Tese (Doutorado em Engenharia Florestal) Universidade Federal do Paraná, Curitiba, 2005. 
PEZZOPANE, J. E. M.; OLIVEIRA NETO, S. N.; VILELA, M. F. Risco de incêndio em função da característica do clima, relevo e cobertura do solo. Floresta e Ambiente, v.8. n.1, p.167-166, 2001.

SAMPAIO, O. B. Estudo comparativo de índices, para previsão de incêndios florestais, na região de Coronel Fabriciano, Minas Gerais1991. 88f. Dissertação (Mestrado em Ciência Florestal) Universidade Federal de Viçosa, Viçosa, MG, 1991.

SAMPAIO, O. B. Análise da eficiência de quatro índices na previsão de

incêndios florestais para a região de Agudos - SP. 2005. 157f. Tese (Doutorado em Engenharia Florestal) - Universidade Federal do Paraná, Curitiba, 1999.

SANTOS, J. F.; SOARES, R. V.; BATISTA, A. C. Evolução do perfil dos incêndios florestais em áreas protegidas no Brasil, de 1993 a 2002.

Floresta, v.36, n.1, p.93-100, 2006.

SILVA, J. C. et al. Avaliação de brigadas de incêndios florestais em unidades de conservação. Revista Árvore, v.27, n.1, p.95-101, 2003.

SOARES, R. V. Incêndios florestais: controle e uso do fogo. Curitiba: Fundação de Pesquisas Florestais do Paraná, 1985. 213p.
SOARES, R. V. Queimas controladas: pós e contras. In: FÓRUM NACIONAL SOBRE INCÊNDIOS FLORESTAIS, 1., 1995, Piracicaba. Anais... Piracicaba: IPEF, 1995. p.6-10.

SOARES, R. V.; SANTOS, J. F. Perfil dos incêndios florestais no Brasil de 1994 a 1997. Floresta, v.32, n.2, p.219-232, 2003.

STATSOFT. Statistica for Windows Computer program manual. Tulsa: 1995.

TORRES, F. T. P. Análise da ocorrência de incêndios em vegetação da área urbana de Juiz de Fora, MG. 2008. 65f. Dissertação (Mestrado em Ciência Florestal) Universidade Federal de Viçosa, Viçosa, MG, 2008.

TORRES, F. T. P.; RIBEIRO, G. A. Índices de risco de incêndios florestais em Juiz de Fora/MG. Seropédica: Floresta e Ambiente, v.15 n.2, p.30-39, 2008.

TORRES, F. T. P. et al. Incêndios em vegetação na área urbana de Juiz de Fora: Minas Gerais. Ubá: Geographica, 2008. 80p.

VOSGERAU, J. L. et al. Avaliação dos registros de incêndios florestais no Estado do Paraná no período de 1991 a 2001. Floresta, v.36, n.1, p.2332, 2006. 